\title{
COMPREHENSIVE ANALYSIS OF OUTRIGGER BUILDING SYSTEM
}

\author{
Thejas H K \\ CHRIST (Deemed to be University), Faculty of Engineering, Bengaluru, India \\ Laxmi S \\ CHRIST (Deemed to be University), Faculty of Engineering, Bengaluru, India \\ Abhilash D T \\ Adichunchanagiri Institute of Technology, Chikmagaluru, India
}

\begin{abstract}
This paper presents a brief understanding of the concept of Outrigger system and explains its structural composition, Nowadays, in modern tall buildings, lateral loads induced by wind or earthquake forces are often resisted by a system of multioutriggers. An outrigger is a stiff beam that connects the shear walls to exterior columns. When the structure is subjected to lateral forces, the outrigger and the columns resist the rotation of the core and thus significantly reduce the lateral deflection and base moment, which would have arisen in a free core. During the last three decades, numerous studies have been carried out on the analysis and behavior of outrigger structures. But this question is remained that how many outriggers system is needed in tall buildings, This paper deals with the comparison of core building without outrigger, with single outrigger and double outrigger
\end{abstract}

Keywords: Tall Buildings, Outrigger Building System, Storey Shear, Lateral Displacement.

Cite this Article: Thejas H K, Laxmi S, Abhilash D T, Comprehensive Analysis of Outrigger Building System. International Journal of Civil Engineering and Technology 11(1), 2020, 25-31.

http://iaeme.com/Home/issue/IJCIET?Volume=11\&Issue=1

\section{INTRODUCTION}

The construction of tall structures in an urban environment has become common in our modern world. This has definitely become a norm since space or real estate is such an important commodity in cities, thereby making structures goes sky high. With this demand comes safety, security and serviceability of these structures so as not to scare its tenants due to the effects of wind and earthquakes. Therefore it is imperative that tall structures require surgical structural analysis prior to its construction in the ground. In places like Japan, China, Taiwan and other Middle Eastern countries tall structures have become a common 
synonymous in the region due to their economic boom and prosperity. Also these countries have something else in common - they frequently experience natural destructive forces such as earthquakes, typhoons and cyclones. So the work of the structural engineer is to find new innovative concepts in order to make tall structures safe. Tall building development has been rapidly increasing worldwide introducing new challenges. As the height of the building increases, the stiffness of the building reduces. There is no clear definition of what a tall building is but according to the Council of Tall Buildings and Urban Habitat (CTBUH) it should have one of the following elements to be considered a tall building

- Height relative to context - When a building is distinctly taller than an urban norm.

- Proportion - A tall that is slender enough to give an appearance of a tall building.

- Tall building technologies - The building contains technologies that are a product of the buildings height, such specific vertical transportation technologies and structural wind bracing.

From a structural engineer's perspective a building would be considered tall when lateral loads, i.e. or earthquakes, play a significant part in the buildings structural design.

\section{OUTRIGGER BUILDING SYSTEM}

The outrigger is an efficient structural form that consists of a central core with outriggers, connecting the core to the outer columns. The central contains of either braced frames $r$ shear walls. Outrigger systems have been historically used by sailing ships to help resist the wind forces in their sails, making the tall and slender masts stable and strong. The core in a tall building is analogous to the mast of a ship, with outriggers acting as the spreaders and the exterior columns like the stays. As for the sailing ships, outriggers serve to reduce the overturning moment in the core that would otherwise act as pure cantilever, and to transfer the reduced moment to the outer columns through the outriggers connecting the core to these columns. The core may be centrally located with outriggers extending on both sides or in some cases it may be located on one side of the building with outriggers extending to the building columns on the other side. When the building is located on one side of the building with outriggers extending to the building columns on the other side. When the building is loaded laterally the vertical plane rotations are resisted by the outriggers through tension in the windward columns and compression in the leeward columns. This is augmenting the lateral stiffness of the building and reducing the lateral deflection as well as the moments in the core.

The outriggers are generally in the form of trusses in steel structures, or walls in concrete structures, that effectively act as stiff headers inducing tension-compression couple in the outer columns. Belt trusses are often provided to distribute these tensile and compressive forces to a large number of exterior frame columns. Outriggers can also be supported on mega columns in the perimeter of the building. Although this structure is primarily an interior system, the belt trusses or mega columns offer a wider perimeter, thus resisting the lateral push of the building's feet spread. For buildings between about 30 to 70 stories, steel braced cores or reinforces concrete core walls are generally effective for resisting lateral loads. However for greater heights, the resistance of the core systems to bending caused by overturning becomes progressively inefficient. Moreover a core system with its highly slender attribute can generate excessive uplift forces in the core columns and high overturning forces on the foundation system. In reinforced concrete cores, excessive wall elements where large net tensile forces develop can easily cancel the inherent efficiency of concrete in compression. Likewise in steel cores excessive welded or bolted tensile splices could greatly reduce the ease of erection and fabrication. The core-outrigger system alleviates this problem. Some 
other advantages of the core-and-outrigger system are that the exterior column spacing can easily meet aesthetic and functional requirements and the building's perimeter framing system may consist of simple beam-column framing without need for rigid-frame type connections. For supertall buildings, connecting the outriggers with exterior mega columns opens up the façade system for flexible aesthetic and architectural articulation thereby overcoming a principal drawback of closed form tubular systems. In addition outrigger systems have a great height potential up to 150 stories and possibly more. The principal disadvantages are that the outriggers interfere with the occupiable or rentable space and the lack of repetitive nature of the structural framing results in a negative impact on the erection process. However these drawbacks can be overcome by careful architectural and structural planning such as placing outriggers in mechanical floors and development of clear erection guidelines. The outrigger systems maybe formed in any combination of steel, concrete and composite construction. Because of the many functional benefits of outrigger systems and the advantages outlined above, this system has lately been very popular for supertall buildings all over the world.

\section{MODEL DESCRIPTION}

The modelling of the structure was done using the software ETABS 2015. ETABS which stands for Extended Three-dimensional Analysis of Building System is commonly used software for the primary purpose of modelling structures of any form or shape in order to analyze the same in a real scenario.

The model is a three dimensional 60 storey tower. Analysis is first done for the model having just the core which is coded as Model 1 or (M1). The next analysis is done for the same structure but this time with the addition of the outrigger at one level, This is Model 2 or (M2). Similarly the results are obtained and compared with the initial model. Next the modelling and analysis of the next and final model which is Model 3 or (M3) with core and double outriggers.

\subsection{Materials \& Member Dimensions}

- Concrete - M60

- Reinforcement Steel - HYSD Fe 415

- Column Size - 750mm x 750mm

- Beam Size - 230mm x 450mm

- Slab thickness $-230 \mathrm{~mm}$

- Shear Wall thickness - 230mmOutrigger Wall thickness - 500mm

- Height of each storey $-3.6 \mathrm{~m}$

- Number of stories -60

- Total Height of Building - 216m 

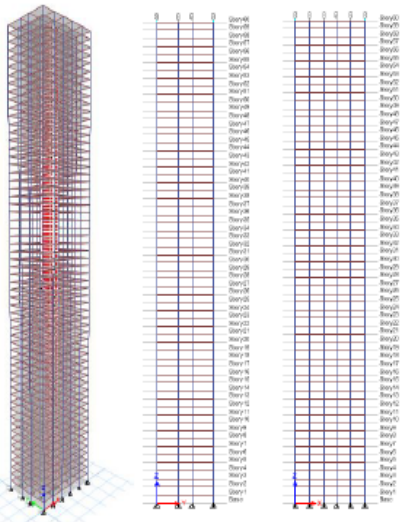

Figure.1. 3D and elevation views of Model 1 - Structure with core wall only
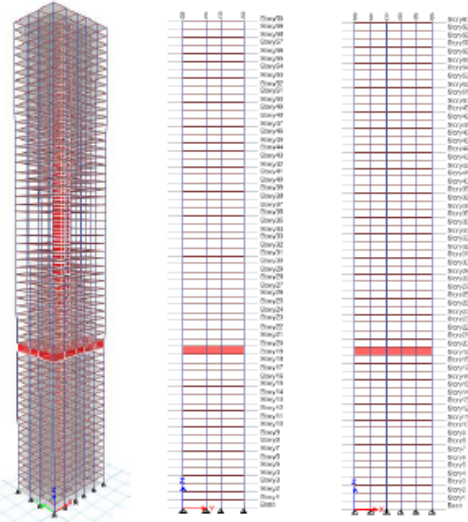

Figure.2. 3D and elevation views of Model 2 - Structure with core wall and single outrigger
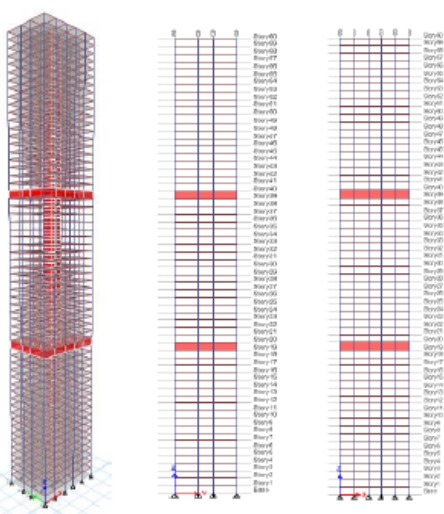

Figure.3. 3D and elevation views of Model 2 - Structure with core wall and double outrigger

\subsection{Loading Cases}

The following loads are considered in the current research

1. Self-weight of members

2. Floor and finishing loads $=1.5 \mathrm{kN} / \mathrm{m}^{2}$

3. Wall load that is UDL on horizontal frames $=6 \mathrm{kN} / \mathrm{m}$

4. Live load on floors $/ \mathrm{slabs}=3 \mathrm{kN} / \mathrm{m}^{2}$

5. Earthquake and wind load with following parameters

- Place - Bangalore

- $\quad$ Seismic Zone = II

- $\quad$ Importance Factor $(\mathrm{I})=1.0$

- $\quad$ Soil Type $=$ Medium

- $\quad$ Seismic Zone Factor $=3$

- Damping $(\%)=5 \%$

\section{RESULTS \& DISCUSSIONS}

\subsection{Lateral Displacements}

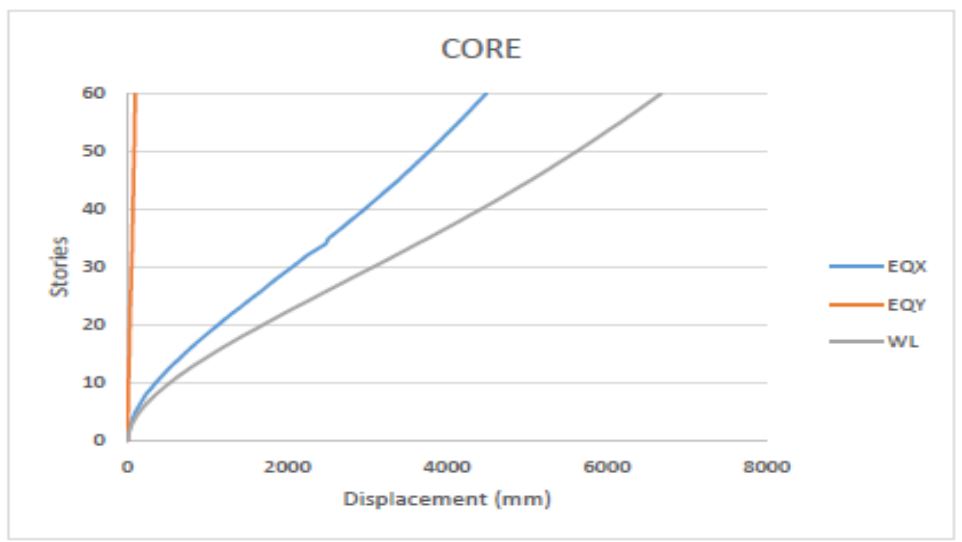

Figure.5. Variation in lateral displacement for M1 under earthquake and wind loads 


\section{Thejas H K, Laxmi S, Abhilash D T}

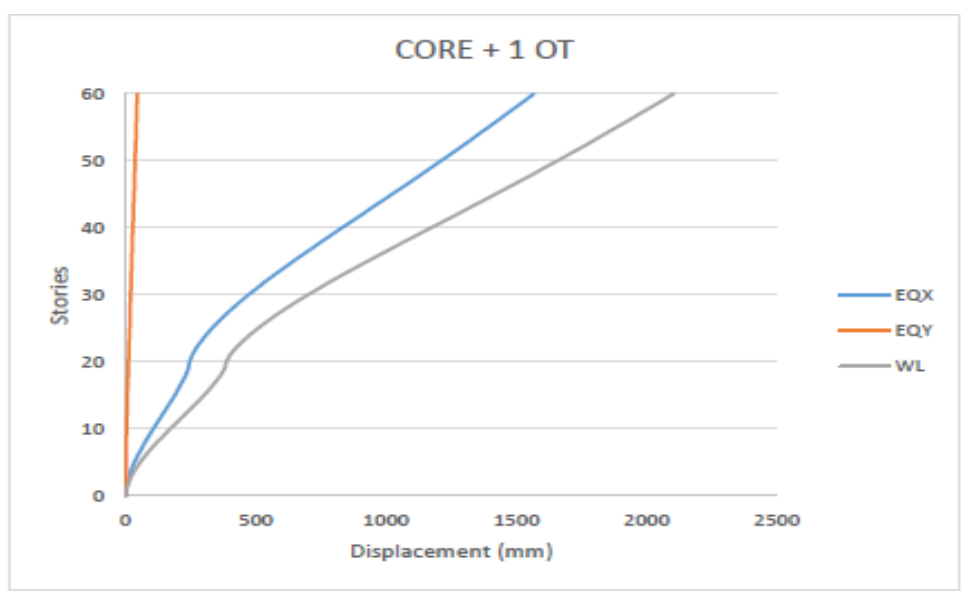

Figure.6. Variation in lateral displacement for M2 under earthquake and wind loads

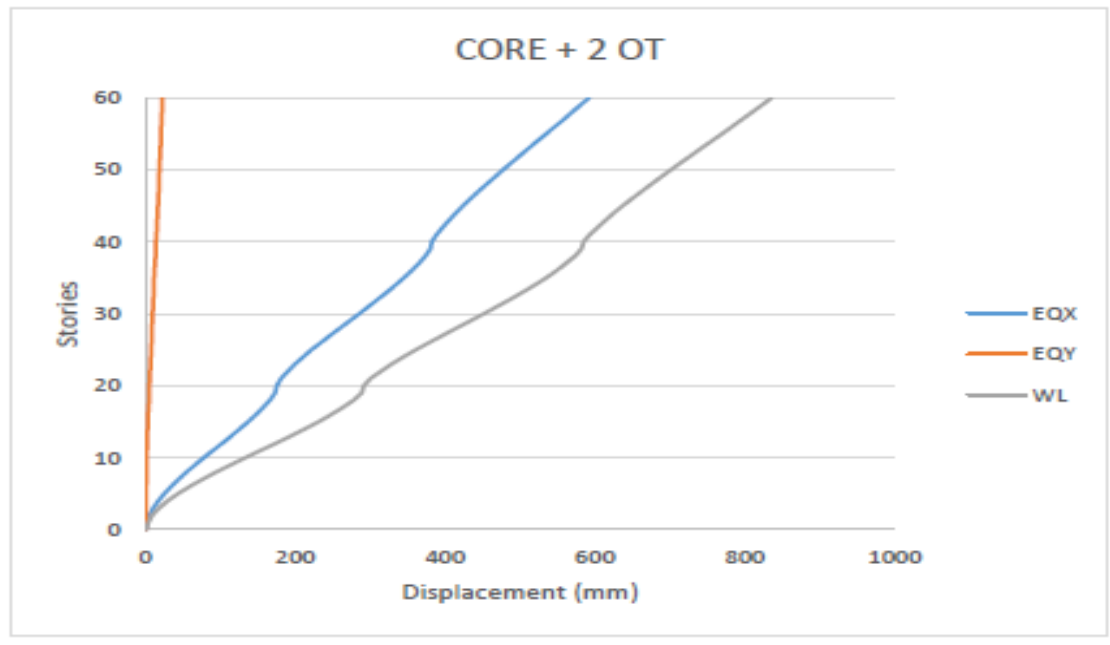

Figure.7. Variation in lateral displacement for M3 under earthquake and wind loads

\subsection{Storey Shear}

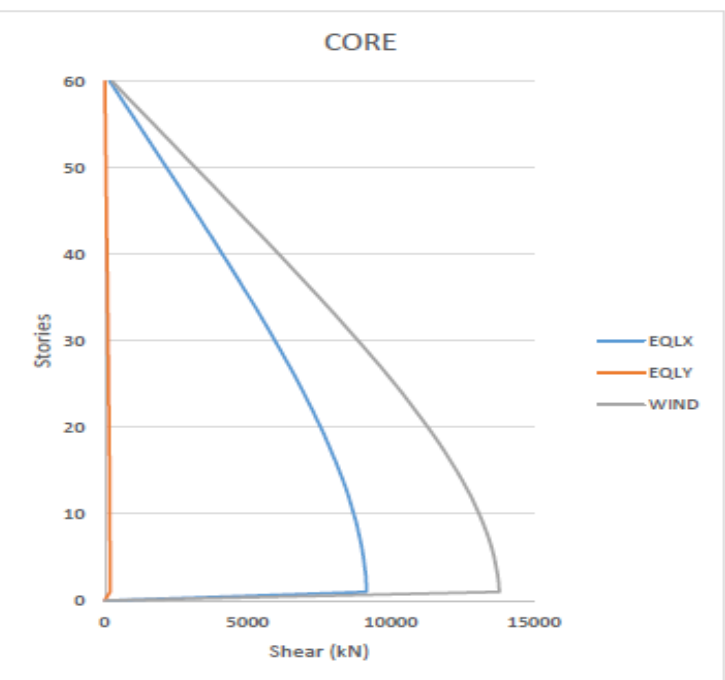

Figure.8. Variation in storey shear for M1 under earthquake and wind loads 


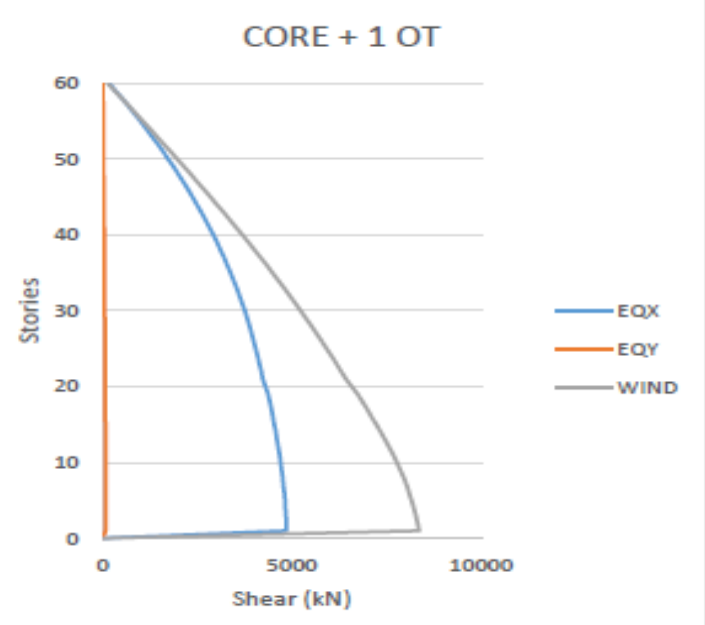

Figure.9. Variation in storey shear for M2 under earthquake and wind loads

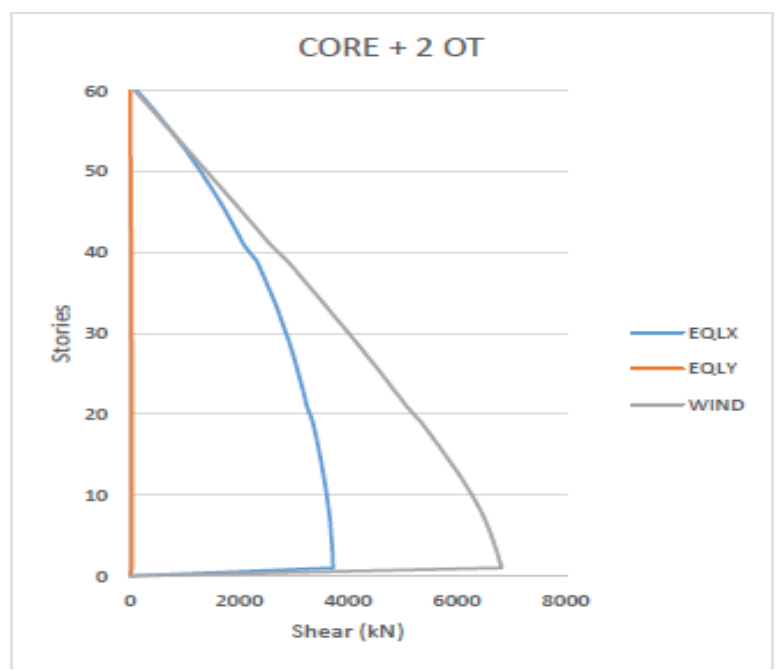

Figure.10. Variation in storey shear for M3 under earthquake and wind loads

\section{CONCLUSION}

From the analysis and retrieving of results the following conclusion can be made for the outrigger building system. The analysis shows the nature and performance of the outrigger structure. As mentioned earlier the models that were modelled were tested for parameters such as lateral displacement and storey shear. From the results obtained the following conclusions can be made regarding adopting outrigger building systems.

- The performance of the structure with outriggers drastically and efficiently reduces the responses. It can also be seen that increasing the number of outrigger levels can improve the overall dynamic performance.

- For single outriggers, the lateral displacements were found to be in a maximum reduction of $68.51 \%$ and for storey shear it is $60.71 \%$.

- For double outriggers the lateral displacements was found to be in a maximum reduction of $87.49 \%$ and for storey shear it is $80.81 \%$. 


\section{REFERENCES}

[1] Smith, "Parameter Study of Outrigger Braced Tall Building Structures", Journal of the Structural Division, Volume no.107, No 10, October 1981.

[2] Rutenberg and Tal, "Lateral Loads Response of Belted Tall Building Structures", Engineering Structures, Volume 9, Issue 1, January 1987, Page no. 53-67.

[3] Gatti and Ishak, "Structural Behaviour of Tall Buildings Stiffened by Outriggered Thin Wall Cores", Multi-purpose High-rise Towers and Buildings, 1997, Page no. 2-6

[4] Hoenderkamp and Bakker, "Analysis of High-rise Braced Frame with Outriggers", The Structural Design of Tall Buildings and Stuctures, Volume 12, 2003, Page no. 335-350.

[5] $\mathrm{Wu}$ and $\mathrm{Li}$, "Structural Performance of Multi-Outrigger Braced Tall Buildings", The Structural Design of Tall and Special Buildings, Volume 12, 2003, Page no. 155-176.

[6] Zhang, Zhang, Zhao, Zhu and Zhou, "Safety Analysis of Optimal Outrigger Location in High-rise Building Structures, Journal of Zhejiang University Science A, Volume 8 (2), 2007. Page no. 264-269.

[7] Smith and Willford, "The Damped Outrigger Concept for Tall Buildings", The Structural Design of Tall and Special Buildings, 16, 501-507, November, 2007.

[8] Bayati, Mahidikhani and Rahaei, "Optimized Use of Multi-Outrigger System to Stiffen Tall Buildings", The 14th World Conference on Earthquake Engineering, October 2008, Page no.12-17, Bejing, China. 